\title{
Entre el "desorden" y el progreso: Una crítica al proyecto modernización política ecuatoriano en la novela Vida del ahorcado (novela subjetiva), de Pablo Palacio
}

\author{
Recibido: $\quad 29$ de agosto, 2019. \\ Aceptado: 12 de octubre, 2020.
}

Por: Mtr. Roberto Antonio Blanco Ramos ${ }^{1}$, Universidad Braulio Carrillo de Costa Rica, Costa Rica, ORCID: 0000-0001-5831-1555.

\section{Resumen}

Durante los primeros decenios del siglo XX las tendencias dominantes de la narrativa hispanoamericana se vincularon con un marco de representación que pretendía reflejar la realidad de su tiempo. Uno tendiente a representar las desigualdades generadas por el desarrollo de los estados nacionales y del capitalismo. No obstante, en ese mismo periodo, surgió, a raíz de la asimilación de la vanguardia histórica, una narrativa que dio lugar a nuevas formas de abordar la realidad literaria.

En ese contexto, el escritor ecuatoriano Pablo Palacio publicó la novela Vida del Ahorcado (Novela Subjetiva), en la que asumió una crítica al proyecto de modernización política ecuatoriana de finales del siglo XIX y de las tres primeras décadas del XX, a partir de una visión narrativa fragmentaria sobre la contradicción del orden simbólico de la modernización. En ese sentido, esta investigación literaria propone analizar la forma en que se construyó dicha crítica, mediante la examinación los principales ejes estilísticos vanguardistas presentes en la novela.

La investigación se divide en cuatro apartados. En el primero, se expone un estado de la cuestión con el objetivo de conocer los principales antecedentes del estudio crítico de la obra palaciana. En el segundo, se desarrolla una contextualización histórica de la realidad socioeconómica y política del proyecto de modernización. En el tercero, se examinan las principales tendencias vanguardistas que la novela contiene. Finalmente, en el cuarto apartado, se realiza el análisis discursivo propuesto.

Esta investigación, se desarrolló como trabajo final del curso Crisis del realismo y fundadores de la nueva narrativa, en el Máster Universitario de Literatura Hispanoamérica, impartido en la Universidad Complutense de Madrid durante el periodo 2018-2019.

1 El máster Roberto Antonio Blanco Ramos es profesor de los cursos de investigación e historia en la Universidad Braulio Carrillo de Costa Rica, Costa Rica. Contacto: robertoblanco1890@ gmail.com.
Roberto Antonio Blanco Ramos. Entre el "desorden" y el progreso: Una crítica al proyecto modernización política ecuatoriano en la novela Vida del ahorcado (novela subjetiva), de Pablo Palacio. Revista Comunicación. Año 41 , volumen 29, número 2, julio-diciembre, 2020. Instituto Tecnológico de Costa Rica. ISSN: 0379-3974 / e-ISSN1659-3820.

\section{PALABRAS CLAVE:}

literatura latinoamericana, narrativa, modernización, política, Ecuador, nación.

KEY WORDS:

Latin American literature, narrative, modernization, politics, Ecuador, nation. 


\section{Abstract}

\section{Between "disorder" and progress: A critique of the Ecuadorian political modernization project in the novel La Vida del ahorcado (novela subjetiva), by Pablo Palacio.}

During the first decades of the 20th century, the dominant trends in Hispanic American narrative were linked to a framework of representation that sought to reflect the reality of its time, one that tended to represent the inequalities generated by the development of nation-states and capitalism. Nevertheless, during this same period, the assimilation of the historical avantgarde, gave rise to a narrative with new ways of approaching literary reality.

This context sees Ecuadorian writer Pablo Palacio publish the novel Vida del Ahorcado (Novela Subjetiva), which criticizes the project of Ecuadorian political modernization in the late 19th and first three decades of the 20th century, based on a fragmentary narrative vision of modernity's contradictory symbolic order. In this sense, this literary study proposes to analyze the way in which this critique was constructed by examining the main avant-garde stylistic axes present in the novel.

The research is divided into four sections. The first analyzes investigations related to the critical study of Palacio literature, while the second section develops a historical contextualization of the socioeconomic and political reality of the modernization project. The third on the other hand examines the main avant-garde trends contained in the novel. Finally, in the fourth section, the proposed discursive analysis is carried out.

This study was the final project for the course "Crisis del realismo y fundadores de la Nueva Narrativa," of the master's degree in Hispanic American Literature, taught at the Complutense University of Madrid from 2018 to 2019.

\section{INTRODUCCIÓN}

En el año de 1932, en un contexto sociopolítico y cultural que demandaba una literatura de realismo social, el escritor ecuatoriano Pablo Palacio publicó la novela Vida del Ahorcado (Novela Subjetiva), la cual significó un cambio trascendental en términos rupturistas, a través de la utilización de una serie de características estilísticas vinculadas con la llamada Vanguardia histórica.

La obra narrativa de Palacio, nacido en el año de 1906 y fallecido en el año de 1947, estuvo sujeta a una determinada coyuntura sociohistórica, la cual pretendió reflejar a partir de una representación desmitificadora y desacralizada de la realidad. En esta, se dieron una serie de conflictos y etapas transitorias, ocurridas desde finales del siglo XIX, en las que se expandió y consolidó un proceso de modernización, marcado por dos relevantes etapas: una de corte liberal capitalista y otra de renovación política estatal.

Con base en las ideas anteriores, el objetivo general del trabajo es analizar la forma en que realiza una crítica al proceso de modernización político ecuatoriano que abarca el periodo histórico de 1895 a 1925, a partir de una representación narrativa vanguardista. Asimismo, siguiendo este esquema gene- ral, se examinan una serie de aspectos sociohistóricos con el objeto de investigar el desarrollo del proyecto del Estado-Nación, el cual apeló, al igual que en otras naciones latinoamericanos, a un imaginario de orden y progreso. De igual modo, considerando el proceso de construcción histórica vanguardista, se examinan los principales ejes estilísticos integrados en la crítica que realiza el autor. Finalmente, con las dos especificidades anteriores, se delimita el marco de análisis rupturista y simbólico presente en novela Vida del ahorcado (novela subjetiva).

En términos teóricos, el análisis parte de los planteamientos de Anderson (2006) sobre la formación sociohistórica de la nación como una comunidad imaginada De acuerdo con el autor, una nación es una comunidad política imaginada como inherentemente limitada y soberana. Es imaginada debido a que se nutre de los actos históricos realizados en periodos predecesores a la constitución de la nación. Es limitada porque debe poseer fronteras finitas con respecto a otras naciones. Finalmente, se autodenomina soberana al aludir a que esta concepción rompe con los esquemas del Antiguo Régimen o, en el caso latinoamericano, con la monarquía española. De esta categoría, además, se derivan otras líneas de interpretación importantes, debido a que permite analizar el 
entramado ideológico y económico sobre el cual se cimentaron los principios de modernización política del estado-nación ecuatoriano.

Lo anterior, debido a tres razones fundamentales. En primer lugar, debe considerarse, tal como lo sostiene Fernández (2009), que dentro del caso latinoamericano, existe el señalamiento teórico que postula cómo la construcción del Estado antecedió a la existencia de nación, debido a que las reflexiones y debates sobre la misma emergen de las declaraciones de independencia y lo largo del siglo XIX (Fernández, 2009, p.3). Este señalamiento nos permite entender la categoría de Nación sin separarla del enfoque institucional que crea la noción de Estado, como proyecto político.

En segundo lugar, el desarrollo de la nación surge, para el caso latinoamericano, como una creación histórica, producto del fenómeno de la modernidad, en un contexto de expansión y consolidación del capitalismo (Ospina, 1996). La nación se configuró a través de la interacción de un sistema de producción y sus relaciones con el mercado. (Fernández, 2009; Ayala, 2002).

En tercer lugar, una nación se fortalece por medio de una comunidad de interés en común, de una élite estatal e intelectual, que promueve la reiterada postulación de discursos de carácter fundacional que legitiman el proyecto propuesto. Estos fueron discutidos en diversos momentos a través de diversas vertientes, incluida la literaria. La corriente vanguardista, en ese sentido, postuló un cuestionamiento, tal como lo realizó Palacio en su novela, sobre esta discursividad.

Por su parte, la noción teórica de vanguardia que guía esta investigación parte de la concepción de vanguardia histórica. Esta se refiere a cómo la vanguardia europea o europeizante, influyó a la literatura ecuatoriana e hispanoamericana en las primeras décadas del siglo XX, en el entendimiento histórico de la recepción de tendencias y corrientes literarias innovadoras (Robles, 1988).

Junto a esta influencia, se entiende la categoría a partir de los planteamientos teóricos de Pöppel y Gomes (2008), quienes, además de entenderla desde la vertiente histórica, la postulan a partir de las concepciones artísticas rupturistas a las que apeló. De acuerdo con los autores, esta corriente buscó la transformación del arte y la literatura con la utilización de una experimentación que rompiera con esquemas de percepción y de sensibilidad. Asimismo, borró fronteras entre el arte y la literatura, lo cual causó la remodelación los géneros literarios; exaltó la diversidad de expresión y apeló a las producciones atrevidas e impactantes (Pöppel y Gomes, 2008; Mantilla, 2018).

El enfoque metodológico de la presente investigación es de carácter cualitativo, ya que se basa en el estudio discursivo de la novela. En esta línea, con el objetivo de comprender y determinar la exposición de la dirección cualitativa de la problemática de estudio, se analiza el carácter descriptivo y simbólico del lenguaje literario expuesto por el narrador y por el personaje principal Andrés Farinago. Es decir, en términos metodológicos, se realiza una indagación basada "en las formas en las que el mundo social es interpretado, comprendido [...] y producido" (Vasilachis, 2006, p.25). Esta dinámica establece el estudio de procesos sociales, de los cambios y del contexto social (Vasilachis, 2006), los cuales son asimilados en la estructuración de la crítica de carácter vanguardista del contexto de modernización sociopolítica.

El trabajo se divide en cuatro apartados. En el primer apartado, se realiza un estado de la cuestión con el objetivo de conocer los principales antecedentes del estudio crítico de la obra palaciana. En el segundo apartado, se expone una contextualización histórica de la modernización política ecuatoriana. En el tercer apartado, se examinan las principales características vanguardistas que contiene la novela, con la finalidad de observar cómo se integran a la perspectiva discursiva que se pretende analizar. Finalmente, en el cuarto apartado, se realiza el análisis discursivo de la novela.

Esta investigación se desarrolló como trabajo final del curso Crisis del realismo y fundadores de la nueva narrativa, en el Máster Universitario de Literatura Hispanoamérica, impartido en la Universidad Complutense de Madrid en el periodo 2018-2019.

\section{PALACIO Y SU LITERATURA: APROXIMACIÓN CRÍTICA DE SU OBRA EN EL MARCO DE LA LITERATURA HISPANOAMERICANA}

En este apartado, se examinan los principales antecedentes bibliográficos sobre la obra del escritor 
ecuatoriano Pablo Palacio, lo cual permite ampliar el marco de interpretación de la problemática que se investiga. La narrativa palaciana se compone por las novelas Débora (1927) y La vida de ahorcado (novela subjetiva) (1932); el cuento Un hombre muerto a puntapiés (1927); los relatos sueltos publicados en revistas ecuatorianas en el periodo que abarca de 1921 a 1930: El Huerfanito, Amor y muerte, El frío, Los aldeanos, Rosita Elguero (historia vulgar), Un nuevo caso de mariage en trois, Gente de provincias, Comedia inmortal, Novela guillotenada, Una mujer y luego pollo frito y Sierra.

De acuerdo con la investigadora Mauro-Castellerín (1997), desde la recuperación y publicación de las obras completas de Palacio en el año de 1964, el estudio de su obra tomó significancia en el contexto de la literatura ecuatoriana, en contraposición con literatura de corte realista y de compromiso sociopolítico. En ese sentido, décadas después, el estudio de su narrativa contempló el carácter innovador y su valor histórico (Mauro-Castellarín, 1997) dentro del desarrollo de las nuevas tendencias narrativas hispanoamericanas surgidas en los primeros decenios del siglo XX, ya que se focalizó en el estudio de las vanguardias literarias y se distinguió como una de las más significativas de ese período.

De esta manera, tres estudios representan un claro antecedente investigativo para el análisis vanguardista de sus obras dentro del contexto histórico que el novelista ecuatoriano construyó en términos literarios. El primero es el texto clásico de Fernández (1991) El realismo abierto de Pablo Palacio en la encrucijada de los 30, publicado en el año de 1991, el cual, hasta el día de hoy, continúa aportando uno de los más exhaustivos análisis de la producción palaciana y su posicionamiento rupturista dentro del periodo sociocultural de la década de 1930. No obstante, su análisis de la novela Vida del ahorcado no contempla una observación que parte del funcionamiento simbólico de un proyecto de Estado- Nación, cuestionado por el protagonista del texto.

El segundo es el artículo de Robles (1988): La noción de vanguardia en el Ecuador: Recepción y trayectoria (1918-1934). En este, delimita la recepción de la llamada vanguardia histórica en la literatura ecuatoriana de las primeras décadas del siglo XX y contempla el papel de escritores como Palacio y Hugo
Mayo. Para el autor, la vanguardia se distinguió en el ecuador por atravesar dos importantes etapas, de las cuales una sirve como base del análisis de la crítica palaciana: "la polémica presencia y recepción de la vanguardia histórica. El descrédito de ésta, en vista de su formalismo y su desfase con el medio y con las normas clásicas" (Robles, 1988, p. 247).

El tercero corresponde al de Mauro-Castellarín (1997), quien consideró, en su artículo Pablo Palacio, precursor de la nueva novela, a Palacio como uno de los más importantes antecesores del posterior surgimiento de la "nueva" novela hispanoamericana en la segunda mitad del siglo XX. Esto debido a que, algunas de las técnicas expuestas en sus obras como el fragmentarismo y el uso monólogo interior y la muestra de una crítica hacia las estructuras de poder, fueron asumidas en las posteriores tradiciones, como la del Boom latinoamericano.

Dicho esto, resulta importante referirse a un nuevo y creciente interés por la literatura palaciana en el siglo XXI. Particularmente, en la realización de tesis de grado, de maestría y de doctorado; así como, en la publicación de ciertos artículos. A partir de una revisión de sus principales enfoques, se lograron establecer los principales abordajes temáticos y teóricos de estas investigaciones:

1. Narrativa de vanguardia, ruptura y transgresión.

2. Representaciones sociales e imaginarios literarios

3. Género, sexualidad e identidades

$\mathrm{Al}$ respecto, debe tomarse en consideración que la mayoría antepone el examen de la vanguardia histórica utilizada por el autor como el eje principal de investigación, de ahí que el punto uno continúa siendo el tema más abordado, tal y como se realiza en este artículo.

\section{LA MODERNIZACIÓN HISTÓRICA ECUATORIANA: 1895-1930}

A continuación, se realiza una contextualización del periodo histórico del cual se nutre la novela de Pablo Palacio y en la que se dinamizan una serie de imágenes desmitificadoras del proceso de modernización ecuatoriana a finales del siglo XIX y en las primeras tres décadas del XX. 
El recorrido, por tanto, debe comenzar con el análisis de la Revolución Liberal. Esta, como en otros estados de América Latina, se fundamentó en la tradición liberal eurocéntrica (Antón, 2014, p. 92). Igualmente, significó un proyecto de transformación nacional, debido a que, a partir de esta, se originaron los procesos sociopolíticos que caracterizaron al territorio ecuatoriano contemporáneo (Vinces, 2017, p.13). Asimismo, es, a partir de los cambios generados en esta etapa, cuando se produjo la consolidación de un régimen capitalista, que atravesó por una serie fases de crisis y transformaciones, las cuales evidenciaron, al mismo tiempo, una contradicción del orden simbólico de modernización (Terán, 2016, p.12).

La Ilamada Revolución Liberal inicia en el año de 1895 y se extiende hasta el año de 1912. Esta coyuntura estuvo supeditada al auge de la exportación cacaotera, la cual provocó la definitiva consolidación del modelo primario agroexportador y el predominio de los sectores capitalistas en la economía. Por consiguiente, la dirección política de la transformación liberal estuvo guiada por una burguesía comercial y bancaria. En palabras de Ayala (2002):

Con el predominio de la burguesía comercial y bancaria de Guayaquil y la movilización de sectores populares rurales y urbanos, se produjo un cambio en la dominación política y mayor apertura a la inserción definitiva del Ecuador en el sistema económico internacional (p. 83).

Por su parte, el proyecto liberal trajo consigo la ruptura de las relaciones entre la Iglesia y el Estado, mediante la puesta en marcha de una serie de medidas de carácter secular (Salvador, 1994). Estas, posibilitaron al Estado retomar el control sobre las amplias esferas que la Iglesia dirigía. Del mismo modo, en este periodo, ocurrió la consolidación decisiva de las libertades y las garantías individuales, emparentadas con el desarrollo y la ampliación de un orden institucionalizado (Salvador, 1994).

De igual forma, como se indicó en la introducción, con el proyecto del liberalismo modernizador, se forjaron las bases de una nación, a través de la adopción y difusión de una serie de medidas conducentes a fortalecer la cohesión nacional de carácter identitario y que, en la Vida del Ahorcado (novela subjetiva) como se analizará en páginas posteriores, el narrador asume desde la crítica irónica de la concepción de patriotismo. Este escenario implicó la decesión:

[...] de construir una identidad, la pertenencia política por medio de la adhesión a un proyecto político en el cual los ciudadanos se ven comprometidos (nacionalismo). Entonces, cuando se funde la nacionalidad con el nacionalismo nace la propuesta de hacer de la comunidad una nación. (Antón, 2014, p.94).

La modernización liberal, en tal caso, se instituyó bajo el principio en el que debe de existir una relación congruente entre unidad nacional y política (Gellner, 2008). De este modo, el concepto de patria propuso un sentido de pertenencia e identificación con una ciudadanía en común. Igualmente, en este proceso de construcción de la identidad se marcaron pautas en términos de diferenciación, lo que creó una frontera interior, la cual se definió por un interior comunitario que apela al 'nosotros' y otro exterior que integra a los 'otros' (Fernández, 2009). En tal sentido, la noción del liberalismo fomentó en las élites blanco-mestizas: "un proceso de homogenización de los sectores subalternos, caracterizados como carentes de potencial político para plantear o constituir una alternativa para pensar el país" (Fernández, 2009, p.5).

En consecuencia, junto al desarrollo de los procesos de la modernización, se trazó un marco de representación de la otredad. Antón (2014) señala que:

La prosperidad de las élites, la urbanización, la industrialización, la concebida modernización llevó a la dependencia y amenazó a sociedades y culturas autóctonas y excluidas. Además, acentuó la injusticia económica. Se advierte que "conforme se intensificó el empuje de la modernización, se hizo inevitable el choque entre los modernizadores y el pueblo, poniendo de relieve la violencia y la relación entre injusticia económica y protesta social (p. 96).

Fue así como la relación de dependencia con el capitalismo establecida desde finales del XIX, coadyubó a que surgieran y expandieran sectores medios y populares. Ayala (2002) señala que: "El liberalismo trajo consigo nuevos actores sociales y una nueva forma de ver la patria, un proyecto nacional que intentaba integrar regionalmente al país e incorporar a 
la comunidad cultural del Ecuador grandes grupos medios y campesinos costeños" (p.83).

Ahora bien, estos nuevos actores, de manera paulatina, deslegitimaron el proyecto nacional y, en la novela de Palacio, adquieren un rol significativo a través de su apelación como sujetos surgidos de las contradicciones y de las discordancias capitalistas.

En síntesis, los cambios implementados por el liberalismo estuvieron orientados a consolidar los mecanismos de reproducción del sistema capitalista con la finalidad de establecer un orden social que se acoplara a los ideales de modernización del orden y progreso.

De esta manera, la etapa que abarca de 1912 a 1925, como lo apunta Ayala (2008), marcó el auge de la oligarquía liberal con el establecimiento de un régimen plutocrático. Además, comenzó una fase que cuestionó los alcances del liberalismo, la cual propició las condiciones de su caída. En tal caso, de acuerdo con el Terán (2016) el contexto plutocrático: "era acechado por los sectores medios y de trabajadores que habían surgido con el liberalismo, por lo que la concentración del poder político estaba relacionada con un descontento social" (p. 25).

Aunado a este escenario, la presencia de una coyuntura de crisis económica de la producción cacaotera, suscitada por la Primera Guerra Mundial, ocasionó la emergencia de organizaciones obrero-artesanales, sindicales y estudiantiles, asociadas a nuevos planteamientos ideológicos, lo cual causó un periodo significativo de conflictividad social.

En virtud de lo anterior, las demandas de estos sectores fueron asumidas por los militares insurrectos en 1925 (Revolución Juliana). Estas sirvieron para renovar el imaginario de progreso y desarrollo nacional (Terán, 2016). La llamada Revolución Juliana generó una modernización estatal acorde con la con la protección de los sectores subalternos y el incremento de clases medias. Este proceso concuerda con el planteamiento de una organización estatal concreta, es decir, el proyecto nacional las fortalece desde una dinámica de poder y de control social. El contexto progresista de esta revolución fue descrito en la Vida del Ahorcado (novela subjetiva) al remitirse la expansión de la estructura estatal de justicia, tal como lo muestra el siguiente fragmento:
[...] No creo que los Anales del Crimen de este pacífico y progresista país registren un caso de delincuencia igual al que nos tiene aquí congregados en demanda de justicia. La sociedad escandalizada, como un solo hombre, ha venido a pedir castigo ejemplarizador contra el culpable. Tiembla la palabra en los labios y la lengua humana se resiste a pronunciar su nombre y a narrar el hecho nefando que lo retiene ahí, en el banquillo de los acusados, [...] (Palacio, 2009, p. 72).

\section{LA VANGUARDIA HISTÓRICA EN LA VIDA DEL AHORCADO}

En las primeras décadas del siglo XX, las tendencias dominantes de la narrativa hispanoamericana buscaban ofrecer al lector un marco de representación de la realidad de su tiempo. No obstante, en ese mismo periodo, paulatinamente se desarrollaron nuevas tendencias narrativas que cuestionaron el compromiso literario con el realismo sociopolítico.

Con respecto a Ecuador, el realismo social se posicionó como una de las principales corrientes literarias del Ecuador a raíz del contexto de conflictividad social, surgido desde finales del siglo XIX, señalado en el apartado anterior. De acuerdo con Salazar (2015), la principal tendencia del realismo social y que la crítica literaria constantemente destaca es la del Ilamado "Grupo de Guayaquil" que agrupa a los siguientes escritores: José de la Cuadra, Enrique Gil Gilbert, Joaquín Gallegos Lara, Demetrio Aguilera Malta y Alfredo Pareja Diezcanseco.

Empero, junto con el desarrollo del realismo, la tendencia vanguardista también se estableció en algunas vertientes. Manozoni (2000), señala que: "las propuestas vanguardistas se instalan en Ecuador casi al mismo tiempo que en otros lugares del continente" (p. 448). Por ejemplo, una clara manifestación del desarrollo, asimilación y difusión de las concepciones artísticas de la vanguardia histórica se dio con la publicación de las revistas Hélice, Esfige y América (Fernández, 1991). Estas se reconocieron bajo el signo de lo nuevo y lo transgresor.

Para el caso específico de la literatura, la noción literaria de vanguardia asumida en Latinoamérica, de acuerdo con la investigadora Mauro-Castellarín (1997) representó: 
[...] un movimiento fundamental de ruptura y de sustitución de los tradicionales códigos del realismo. La sustitución, la inclusión, la compenetración de códigos procedentes de otras artes y ciencias hicieron posible el surgimiento de un nuevo modelo estético, la ruptura abarcaba tanto a los códigos como a los géneros. El texto, mediante la construcción de un nuevo metalenguaje, se constituye, de este modo, en un modelo de representación de la realidad en sus múltiples posibilidades y combinaciones (p. 382).

Por ende, en ese marco de innovación y ruptura, se inscribió la novela de Palacio: Vida del ahorcado (Novela Subjetiva). Para Mauro-Castellarín, (1997) su contenido vanguardista transgrede con:

[...] todos los cánones clásicos del género, tal como lo indica el subtítulo, el contenido es una pura inmaterialidad, es simplemente el desarrollo de una conciencia y de una introspección que va enlazando imágenes, recuerdos, escenas de amor, coros teatrales en un largo ciclo que abarca desde una mañana de mayo, pasando por algunas escenas que corresponden al mes de junio, hasta llegar a agosto, setiembre y octubre (pp. 390-391).

La exposición señalada por Mauro-Castellarín (1997) permite identificar, de una manera más detallada, la estética rupturista a la que apeló su visión representativa de la modernización política de finales del siglo XIX y principios del XX. Además, sobre la novela que es objeto de análisis, los textos palacianos se inscriben dentro de una crítica de los discursos políticos, sociales y jurídicos; es decir, aquella discursividad fundacional que legitimó el proyecto de unidad de una nación. Con el realismo, existe un compromiso con la realidad excluyente y desigual formada a raíz del desarrollo histórico del capitalismo dependiente; por el contrario, con la retórica vanguardista palaciana, predomina un quiebre del código tradicional de la realidad: "las rupturas que realiza Palacio, se orientan conscientemente contra dicho código de la representación [...] se proponen desenmascarar la retórica del realismo" (Manzoni, 2000, pp. 448-449).

Si bien en la novela existe una clara referencialidad al otro, su exposición se da con un quiebre simbólico de esa realidad que legitiman los textos realistas. De esta manera, siguiendo los planteamientos de Terán
(2016), la novela presenta una visión narrativa fragmentaria de la contradicción del orden simbólico de la modernización.

En tal caso, no resulta una labor sencilla trazar el eje argumentativo de la obra. El texto se presenta a partir de una serie de fragmentos en los que se exponen diversas temáticas por medio de la parodia, el absurdo y la ironía. Dichos fragmentos, sin embargo, van tejiendo la historia del personaje central y narrador (Andrés Farinango), su vínculo y visión con la realidad sociopolítica, su relación amorosa con Ana, su vínculo con su hijo y su eventual condena.

Para Von Der Pahlen (2014): "en lugar de un argumento en el que se pueda identificar un hilo narrativo principal, hay una serie de reflexiones, episodios y anuncios que se entrecruzan, se enmarañan, se enfrentan o se ignoran" (p. 2). Asimismo, según Ayala (2017):

Vida del ahorcado (novela subjetiva) se presenta de manera discontinua, la constituyen apartados que en un primer momento se podrían asociar con las entradas de un diario [...] el orden ascendente de estas entradas (las primeras) rápidamente da paso a una multiplicidad de apartados aparentemente inconexos entre sí como "hambre", "perro perdido", "hombre con pulgas", etc. Se presentan de manera aparentemente inconexa pues cada uno revela un sentido, cada uno se presenta como una pieza del gran collage que es la novela y nos permiten ser partícipes del mundo creado al interior de ésta, [...] (p. 221-222).

Por ello, el recurso estilístico de la fragmentación resulta fundamental debido a que los diversos apartados constituyen una suerte de alegoría de la sociedad moderna, una en la que se evidencia un momento de transición y de desencanto con la realidad (Fernández, 1991).

Consecuentemente, los criterios que asocian la novela con la Vanguardia histórica son los siguientes: un cuestionamiento a los esquemas de normalidad y el orden institucionalizando, la innovación técnica, una postura crítica a la cultura literaria del momento (realismo social, indigenismo y realismo socialista) y la representación de un proyecto transformador de la sociedad (Robles, 1988). 
Por último, es importante mencionar que las características mencionadas se disponen a través de la utilización de los recursos del humor. Esto con el objetivo de mostrar una crítica desde el plano de lo irónico, en donde lo serio del orden y el progreso, se convierte en ridículo.

\section{EN LA MITAD DE LOS MUNDOS ANTIGUO Y NUEVO: UNA CRÍTICA DEL PROYECTO MODERNIZACIÓN ECUATORIANO EN LA VOZ DE UN PROLETARIO PEQUEÑOBURGUÉS.}

En este apartado, a partir de lo expuesto en los dos anteriores, se analiza la forma en que se establece una crítica de los valores dominantes y de los mecanismos de poder, sobre lo que Andrés Farinango cataloga con un nuevo mundo (Palacio, 2009, p.13). Es decir, el entorno político heredado del liberalismo y su continuación en las primeras tres décadas del siglo XX.

En consecuencia, dicho cuestionamiento se establece en dos vías: la decadencia de la modernización y la oposición al orden literario tradicional. En tal sentido, el esquema de criticidad social y la utilización de recursos estilísticos vanguardistas son proyectados dentro de una misma línea narrativa. En esta línea, para Ayala (2017): "Vida del ahorcado es un claro ejemplo donde se revela, por medio de la amalgama del tema crítico social y el vanguardismo compositivo, una forma nueva de hacer novelas en América Latina" (p. 22).

En las primeras páginas de la novela, Andrés Farinango se autodenomina como un proletario pequeñoburgués que: "ha encontrado la manera de vivir con los burgueses, con los buenos y estimables burgueses (Palacio, 2009, p.13). Este hecho corresponde a uno de los puntos esenciales de su crítica, dado que la dinámica de la estratificación social es asumida en la novela mediante la representación de los diversos sectores y estratos sociales, a través de un discurso que evidencia las contradicciones del capitalismo y la formación de una etapa transitoria que da paso a una modernidad en discordancia, tal como lo evidencia el siguiente párrafo:

He aquí un producto de las oscuras contradicciones capitalistas que está en la mitad de los mundos antiguo y nuevo, en esa suspensión del aliento, en ese vacío que hay entre lo estable y el desbarajuste de lo mismo. Tú también estás ahí, pero tienes un gran miedo de confesarlo porque uno de estos días deberás dar el salto y no sabes si vas a caer de este o del otro lado del remolino. Mas aquí mismo estás enseñando las orejas, amigo mío, tú, enemigo del burgués, que ignoras el lado en donde caerás después del salto. Pero ya me lo aclaras todo: Estoy viviendo la transición del mundo. Aquí, delante de mí, está la volcadura de campana, del otro lado de la justicia, y aquí mismo, dentro de mí, están todos los siglos congelados, envejecidos y grávidos. Yo tengo un amor en estos siglos; yo tengo un amor en esta volcadura (Palacio,2009, pp. 13-14).

Además, Farinango invita a los sectores sociales a un espacio simbólico en el que hay cabida "para cada hombre cada cosa" (Palacio, 2009, p. 13) (su cubo), un espacio que sería la contraposición del modelo de modernización capitalista:

Venid, entrad, señoras y señores burgueses, señoras y señores proletarios. Entrad vosotros los expulsados de todo refugio y los descontentos de todos ellos. Entrad todos vosotros, compatriotas de este chiquito país. Vos, compatriota obeso; vos, compatriota esmirriado; vos, compatriota de la nariz de salchicha; vos, compatriota empolvado; vos, compatriota romántico; vos, compatriota aburrido; vOS, VOS, vos. No habed miedo de no tener sitio. Más bien venid a admirar la capacidad de este cubo de grandes muros lisos y desnudos, en donde todo lo que entra se alarga o se achica [...] Aquí en este cubo hay sitio para todo el mundo (Palacio, 2009, pp.12-13).

Del mismo modo, la exposición de un entorno estratificado da paso a la crítica de las estructuras de dominio, una que refleja la consolidación de un régimen liberal oligárquico. En el pasaje titulado ¡ATENCIÓN! SUBASTA PÚBLICA, por ejemplo, se expone de manera irónica la forma en que la nación debe alcanzarse el progreso económico:

Atención, capitalistas del mundo:

El Chimborazo está en pública subasta. Lo daremos al mejor postor y se admiten ofertas en metálico o en tierra plana como permuta. Vamos a deshacernos de esta joya porque tenemos necesidades urgentes: nuestros súbditos están con 
hambre, por más que tengan promontorios a la ventana. [...] ¡Queremos tierra plana para sembrar caña de azúcar y cacao! ¡Queremos tierra para pintarle caminos! Atención, capitalistas del mundo:

¡Los más hermosos volcanes están en pública subasta! (Palacio, 2009, pp.18-19).

La invitación que realiza Farinango, a "los expulsados de todo refugio y los descontentos de todos ellos" (Palacio, 2009, p.12.) remite a un aspecto esencial de cómo se personifica, a nivel narrativo, el desencanto de la modernización política, el cual es descrito mediante la representación del aislamiento, la ausencia y el encierro en un mundo propio (cubo). Una forma de vislumbrar la selectividad que emprende un proyecto nacional que relega a algunos sectores sociales, representado, en este caso, por un 'otro' personificado en la figura del protagonista.

No estoy aquí; he caído de nuevo en este hueco de la ausencia. ¡Cada vez la sensación de ausencia! Estoy como desintegrado: me parece que partes de mí mismo residen lejos de lo mío, en algún sitio desconocido y helado. Quedo mucho tiempo en tinieblas y empiezo a andar a tientas por todos los rincones del cubo, dominado por sus impulsos contradictorios: la esperanza y el terror de encontrar a alguien que también me busca (Palacio, 2009, pp. 41-42).

La construcción y trascendencia de un Estado-Nación, es otro de los ejes de criticidad que puede interpretarse. En el fragmento titulado Un hombre recapacita, el narrador hace alusión a la noción de compatriota, y su fundamentación desde el poder:

Os place llenar vuestro estómago tres o cuatro veces al día. ¡Coméis tres o cuatro veces al día, compatriotas!

Os place tomaros un vinillo en la tarde del sábado para calentaros el magín y devolver algo más de la comida con que os habéis hastiado. ¡Pero os quedáis con mucha más comida, inapreciables compatriotas!

También os place echar sostenidos paliques sobre los negocios de Estado y sentaros por largas horas con unos papelitos mosqueados ante los ojos, para educar vuestra gran inteligencia. ¡Ay, cómo perdéis inútilmente el tiempo, lamentables compatriotas! (Palacio, 2009, p. 60).

Lo mismo ocurre en el fragmento Sueños, en este, Farinango brinda una explicación paródica a su hijo acerca de cómo debe entenderse la patria y el patriotismo, en la cual destaca la figura del rey y el enaltecimiento de la memoria y el recuerdo para la creación de figuras heroicas:

Los hombres, para ser verdaderos reyes, necesitan hacerse fuertes con fusiles y bayonetas. Aquéllos que continuamente están hechos fuertes toman el nombre de soldados. [...]

Entonces los congéneres de los soldados muertos enaltecieron su memoria y les llamaron patriotas heroicos. Patria es tierra con reyes.

Tú, cosilla mía, llegarás a ser un patriota heroico, o por lo menos jun patriota! Escucha, escucha: esto es lo fundamental. Serás un comerciante patriota, un juez patriota, un ladrón patriota, un artista patriota (Palacio,2009, pp.65-66).

En ese sentido, la alusión de lo heroico debe de entenderse desde el análisis realizado por Anderson (2006), en donde la concepción imaginaria de una nación está conexa con la identificación de figuras históricas y emblemáticas del pasado.

Por lo tanto, si hay cabida para el patriotismo, este debe ser asumido por ciudadanos 'consientes' del orden simbólico y de los valores dominantes de la modernización política de un Estado-Nación. En la novela, a partir de la detención del protagonista, surgen menciones emparentadas con el acatamiento de ese orden:

¿Detenido? Muy... muy bien, señor agente. A su mandar.

Y sigo a los señores agentes del orden. Un ciudadano patriota debe ser obediente y respetuoso. ¡Disciplina, disciplina, amables compatriotas! Disciplina es la base de la prosperidad (Palacio, 2009, p.68).

La disposición narrativa de este esquema disciplinario puede concebirse, en términos sociológicos, desde el Ilamado control social. Es decir, una serie de mecanismos normalizadores del orden a través de los cuales se presiona a los individuos para adherirse a esquemas establecidos (Morales y Márquez, 2001), 
los cuales regularizan la dinámica de poder del proyecto de modernización, y, además, reprimen las conductas desviadas. En tal caso, el título del apartado que narra la detención resulta esencial para comprender esta interpretación: "ORDEN, DISCIPLINA, MORALIDAD" (Palacio,2009, p.67).

Ahora bien, con el arresto de Farinango comienza a percibirse la forma en la cual se presenta una ridiculización de los mecanismos de justicia, enfocada, por medio del cuestionamiento, al orden institucionalizado, reforzado en la coyuntura de modernización política. Esta representación, se fundamenta en la deslegitimación de los saberes consagrados y de las instituciones que resguardan la moral oficial y el orden. En el siguiente ejemplo, se describen algunas de esas instituciones, recalcando su expansión en el ámbito sociocultural y en el de la cotidianidad:

Hola, hola, ¿estás ahí, compañero Tixi? ¿Eres tú, compatriota Alejandro? Hola, Honorables Instituciones, ¡todas vosotras aquí representadas! "Universidad", "Tenderos", "Prestamistas", "Amantes", "Trabajadores sin pan" y más, y más. Oh, ¿pero es que se trata de una fiesta deportiva que habéis traído aquí vuestras banderitas? Tal vez vais a batirlas como en los campeonatos de las Universidades Inglesas. Vaya, ¡qué cosa más interesante! (Palacio,2009, pp.71-72).

De esta manera, su condena simboliza una versión desacralizada de la justicia. La siguiente narración así lo demuestra:

- ¿Lo han oído? ¡Ja, ja, ja, ja! ¡Es un a-hor-ca-do! Entonces debiéramos ahorcarlo

nuevamente. Claro, ya está ahorcado, ¿y qué? ¡Que se lo ahorque! ¡Propongo que se lo ahorque!

Coro:

-Sí, sí. ¡Que se lo ahorque!

- ¡Que se lo ahorque!

El abogado defensor:

-Señor presidente: Esto es una pantomima ¿o qué es? ¿Quién puede entender esta audiencia ridícula?

$[\ldots]$
-Pero, señores del Tribunal, ¿cómo es posible que legalmente pueda darse oídos a una proposición de esa naturaleza? ¿Existe acaso la pena de la horca entre nosotros? Pido que se lean las disposiciones del Código. No existe: esto es un abuso.

- ¡No importa!

- ¡Lo pide el pueblo! (Palacio, 2009, pp. 78-79).

Finalmente, los contenidos expuestos en su condena también evidencian el contraste de las propuestas políticas e ideológicas, surgidas como consecuencia de las contradicciones de la modernidad capitalista, mostradas por medio de un enfrentamiento dialéctico satírico:

¡Protestamos! Es un burgués, y de la peor clase. Es el último burgués. Ya va a descomponerse. Está irremisiblemente perdido. El bolchevique es un hombre alegre y sabe amar la vida porque la toma como ella es, jubilosamente. Es un burgués, ique se lo ahorque! (Palacio,2009, p.82).

\section{CONCLUSIONES}

Esta investigación ha trazado una serie de interpretaciones que se analizarán a continuación. La representación irónica que establece Palacio (2009) del proyecto de modernización política, en el año de 1932, parte de la realidad socioeconómica y política que lo circundó. Por ende, en la novela se relaciona un claro descrédito de la realidad a través de la puesta en marcha de una crítica y un cuestionamiento de la sociedad moderna ecuatoriana de finales del siglo XIX y de las primeras décadas del XX.

En virtud de esto, la novela refleja, mediante un esquema vanguardista de fragmentación, una etapa de transición en la que el protagonista se desencanta con un contexto que apela al progreso, al señalar de forma sarcástica la etapa contradictoria que lo rodea.

Por su parte, a partir de los examinado, es indiscutible que la obra trasciende la lógica de representación literaria que asimila el realismo social descriptivo y reivindicador de los sujetos subalternos. Si bien es cierto que hay una presentación de una dinámica de estratificación social, esta se presenta a partir de una visión desacralizada, en la que se distingue la visión irónica y existencial. 
Por último, los recursos literarios de la novela buscan una suerte de irrupción del entorno sociopolítico, a partir de representaciones simbólicas reflejadas en el lenguaje literario expuesto por el narrador y por el personaje principal Andrés Farinango, las cuales discrepan del esquema de asimilación de los valores dominantes e ideológicos. Esto debido a que muestran una versión paradójica de la construcción de un Estado nacional y de sus mecanismos de cohesión y disciplina.

\section{AGRADECIMIENTO}

El autor desea agradecer a Bethania Guerra de Lemus, profesora del Departamento de Literaturas Hispánicas y Bibliografía de la Universidad Complutense de Madrid, por los comentarios realizados y las sugerencias dadas para la elaboración del presente artículo.

\section{REFERENCIAS BIBLIOGRÁFICAS}

Anderson, B. (2006). Comunidades imaginadas: Reflexiones sobre el origen y la difusión del nacionalismo. México D.F.: Fondo de Cultura Económica.

Antón, J. (2014). El modelo de Estado Plurinacional en Ecuador: ideas y reflexiones. Revista de Antropología Experimental, 7, 91-107. Recuperado de https://revistaselectronicas.ujaen.es/index.php/rae/article/view/1884

Ayala, E. (2002). Ecuador: Patria de todos. La nación ecuatoriana, unidad en la diversidad. Quito: Universidad Andina Simón Bolívar, Sede Ecuador. Disponible en https:// www.uasb.edu.ec/programa?ecuador-patria-de-todosla-nacion-ecuatoriana-unidad-en-la-diversidad

Ayala, E. (2008). Resumen de historia del ecuador. Quito: Corporación Editora Nacional, 2008.

Ayala, I. (2017). Vanguardia y crítica: Vida del ahorcado (novela subjetiva) de Pablo Palacio. Valenciana Estudios de Filosofía y Letras, 20, 215-238. Recuperado de http:// www.revistavalenciana.ugto.mx/index.php/valenciana/ article/view/111

Fernández, B. (2009, noviembre). Crisis del Estado-nación ecuatoriano: Intelectuales indígenas y Estado-plurinacional. Ponencia presentada en $\mathrm{V}$ Jornadas de Jóvenes Investigadores, Instituto de Investigaciones Gino Germani, Facultad de Ciencias Sociales, Universidad de Buenos Aires, Argentina.
Fernández, M. (1991). El realismo abierto de la Pablo Palacio. En la encrucijada de los 30. Quito: Ediciones Libri Mundi.

Gellner, E. (2008). Naciones y nacionalismo. Madrid: Alianza Editorial.

Mantilla, R. (2018). José de la Cuadra y Pablo Palacio: intelectuales en un proyecto de vanguardia enraizada. (Tesis de Maestría en Sociología, Facultad Latinoamericana de Ciencias Sociales, FLACSO Ecuador).

Manzoni, C. (2000). Una estética de ruptura. En Corral, W. (Coor.), Pablo Palacio. Obras Completas (pp.447-464). Madrid\}: ALLCA XX.

Mauro-Castellarín, T. (1997). Pablo Palacio, precursor de la nueva novela. Anales de Literatura Hispanoamericana, 26, 381-394. Recuperado de https://revistas.ucm.es/ index.php/ALHI/article/view/ALHI9797220381A

Morales, J. y Márquez, L. (2001). Introducción a la Sociología. Madrid: Editorial Tecnos.

Ospina, P. (1996). Imaginarios nacionalistas: Historia y significados nacionales en Ecuador, siglos XIX y XX. Procesos. Revista Ecuatoriana de Historia, 9, 111-124. Recuperado de http://repositorio.uasb.edu.ec/handle/10644/1259

Palacio, P. (2009). Vida del ahorcado (Novela Subjetiva). Valencia: El Nadir Ediciones.

Pöppel, H. y Gomes, M. (2008). Las vanguardias literarias en Bolivia, Colombia, Ecuador, Perú, Venezuela. Madrid: Iberoamericana Editorial.

Robles, H. (1988). La noción de vanguardia en el Ecuador: Recepción y trayectoria (1918-1934). Revista Iberoamericana, 144, 224-249.

Romero, J. (1986). Situaciones e ideología en Latinoamérica. Buenos Aires: Editorial Sudamericana.

Salazar, Y. (2015). El género novelístico en la literatura ecuatoriana. Universitas: Revista de Ciencias Sociales y Humanas. 23, 183-203. Recuperado de https:// universitas.ups.edu.ec/index.php/universitas/article/ view/23.2015.09

Salvador, J. (1994). Breve historia contemporánea del Ecuador. México D.F.: Fondo de Cultura Económica.

Terán, D. (2016). Racionalidad geométrica en Vida del ahorcado (novela subjetiva) del Pablo Palacio: alucinamiento en modernización. (Tesis de Maestría en Literatura Hispanoamericana, Universidad Andina Simón Bolívar, Bolivia). Recuperado de http://repositorio.uasb. edu.ec/handle/10644/5504 
Entre el “desorden” y el progreso: Una crítica al proyecto modernización política ecuatoriano en la novela Vida del ahorcado (novela subjetiva), de Pablo Palacio

Vasilachis, I. (2006). Estrategias de Investigación cualitativa. Barcelona: Editorial Gedisa.

Vinces, J. (2016). Construcciones discursivas acerca de civilización y barbarie en el cuento el antropófago de Pablo Palacio. (Proyecto de investigación para obtener el título de Comunicador Social, Universidad Central del Ecuador, Ecuador). Recuperado de http://www.dspace. uce.edu.ec/handle/25000/14087

Von Der Pahlen, M. (2014, marzo). Acerca de una novela subjetiva: Vida del Ahorcado de Pablo Palacio. Ponencia presentada en la XXVI Jornadas de Investigadores del Instituto de Literatura Hispanoamericana, Buenos Aires, Argentina. Recuperado de http://ilh.institutos.filo.uba. ar/sites/ilh.institutos.filo.uba.ar/files/Von\%20der\%20 Pahlen\%2C\%20Marina.pdf. 